\title{
Characteristics Test of Photoresistor and Its Application in Optical Control Switch
}

\author{
Lingbo Wang \\ College of Electronic Information Engineering, Wuhan Polytechnic, Wuhan, Hubei, CHINA \\ email: wlb0125@163.com
}

Keywords: photoresistor; characteristics test; photosensitive resistance; optical control switch

\begin{abstract}
Experimental teaching is important for the professional course; an experimental platform has been designed. Using this photoresistor experimental apparatus, characteristics of photoresistor could be measured, experimental results agree well with the theory. And the platform provides the students open interface and opportunities of building their own optical control circuit, therefore students can understand the principles and operation methods of light control switch applications.
\end{abstract}

\section{Introduction}

Photoresistor is a light-controlled variable resistor made by semiconductor materials, working based on photoelectric effect. In light, the photosensitive resistance often turns smaller, this phenomenon is known as photoelectric effect. While voltage is applied on metal electrodes of photoresistor, current is flowing. When light with appropriate wavelength, current will increase if light intensity turns bigger. Using photoresistor to convert optical signals into electrical signals, and then signals processed by the corresponding instrument, you can achieve automatic control and other purposes.

Using photoresistor experimental apparatus, basic characteristics of photoresistor can be measured; and an optical control switch circuit with photoresistor detected has been designed in this experiment.

\section{Experimental apparatus}

Using photoresistor experimental apparatus, the basic characteristics, such as photo current, dark current, illumination characteristics, spectral characteristics, current-voltage characteristics, and frequency characteristics, and so on, can be studied; then light control switch circuit can be built within this platform.

Both PCB circuit board and optical pathway components are placed within this apparatus, the whole experimental system of optical path is so clear at a glance. PCB circuit board part, equipped with $\sim 12 \mathrm{~V}$ adjustable DC voltage source, can provide voltage for the photo resistor. Voltmeter, ammeter and illuminometer are all in this apparatus, with display units and control units on the panel, so connection, adjustment, observing and recording are all workable on the panel.

\section{Experimental method}

Work principle and basic characteristics of photoresistor. Photoresistors are almost made of semiconductor optoelectronic devices. When photoresistor is exposed to certain wavelengths of light, its resistance (photosensitive resistance) decreases, current in a circuit increases rapidly. It is generally desirable dark resistance the bigger the better, photosensitive resistance the smaller the better, now the photoresistor is with high sensitivity.

\section{Main parameters of photosensitive resistance.}

Dark resistance, in dark, the resistance is high, called dark resistance, the current flows is called the dark current at this time. 
Bright resistance, the resistance of the photoresistor changes with illumination refers to bright resistance, at this time the current flows is called bright current.

Photo current, refers to the difference between bright and dark current.

\section{Basic characteristics of photosensitive resistance.}

Current-voltage characteristic, Current-voltage characteristic, the relationship between current through the photoresistor and the voltage across it under illumination.

Illumination characteristic, the relationship between photo current and light intensity.

Spectral properties: photoresistors have light spectral selection, namely having different sensitivities to different wavelength of the incident light.

Frequency response, light current does not immediately change with light intensity changes, there is always a delay, refer to a time constant. Resistors of different materials have different time constant (ms magnitude), and thus their frequency characteristics vary.

\section{Module of characteristics test.}

Test module. Electronic circuit structure

A voltmeter: independent voltmeters, three switches, $200 \mathrm{mV}, 2 \mathrm{~V}, 20 \mathrm{~V}$, by dialing switch to regulate. "+" "-" correspond to the "positive", "negative" polarity of voltmeter.

An ammeter: independent ammeter, three switches $200 \mu \mathrm{A}, 2 \mathrm{~mA}, 20 \mathrm{~mA}, 200 \mathrm{~mA}$. Dialing switch to regulate. "+" "-" correspond to the "positive ", "negative" polarity of voltmeter.

Fixed resistance value: $\mathrm{R}_{\mathrm{L} 1}=1 \mathrm{~K} \Omega, \mathrm{R}_{\mathrm{L} 2}=2 \mathrm{~K} \Omega, \mathrm{R}_{\mathrm{L} 3}=5 \mathrm{~K} \Omega, \mathrm{R}_{\mathrm{L} 4}=10 \mathrm{~K} \Omega, \mathrm{R}_{\mathrm{L} 5}=20 \mathrm{~K} \Omega, \mathrm{R}_{\mathrm{L} 6}=50$ $\mathrm{K} \Omega, \mathrm{R}_{\mathrm{L} 7}=100 \mathrm{~K} \Omega, \mathrm{R}_{\mathrm{L} 8}=200 \mathrm{~K} \Omega, \mathrm{R}_{\mathrm{L} 9}=500 \mathrm{~K} \Omega, \mathrm{R}_{\mathrm{L} 10}=1 \mathrm{M} \Omega, \mathrm{R}_{\mathrm{L} 11}=2 \mathrm{M} \Omega, \mathrm{R}_{\mathrm{L} 12}=5 \mathrm{M} \Omega$

DC power supply: $\sim 12 \mathrm{~V}$ adjustable " $12 \mathrm{~V}$ " as the positive pole of the power supply and the other end as negative.

Optical path components

Figure 1 is the description of the optical pathway components. Figure 2 is a block diagram of the experiment for measuring feature of photosensitive resistance. Beam-splitting mirrors make the light pass through $50 \%$, and $50 \%$ reflection, half for illumination probe, half for photoresistor; illuminometer can monitor the light on photoresistor during the test.

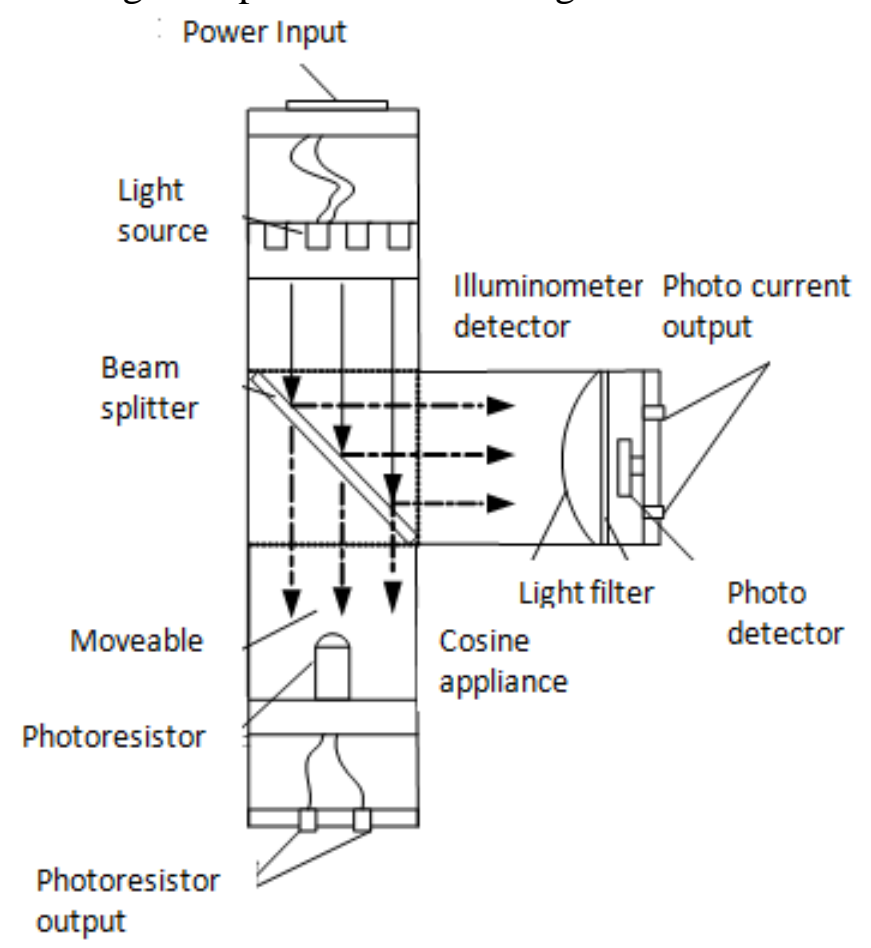

Fig.1 Optical pathway components 


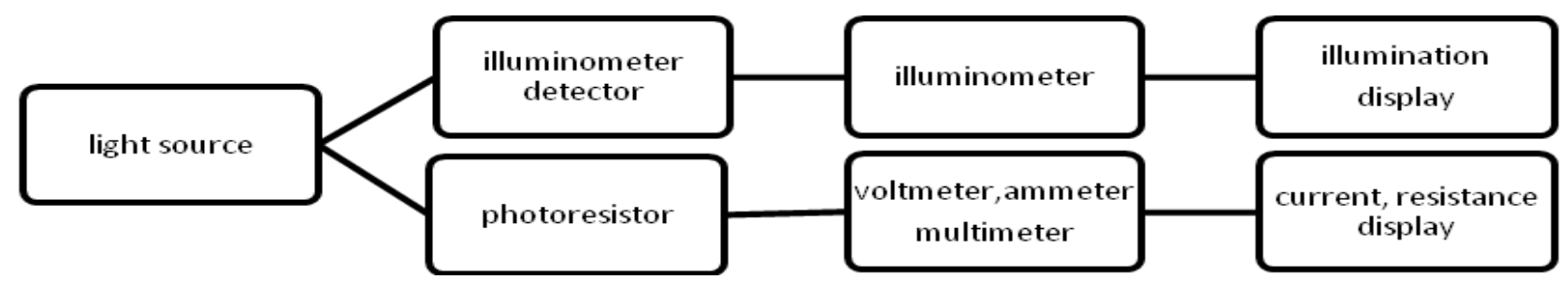

Fig.2 Block diagram of the experiment for measuring feature of photosensitive resistance

Optical switch module. By changing light intensity on the photoresistor, we can control the switching status of the relay, thus control light emitting diodes on and off. Figure 3 is a light control switch circuit diagram.

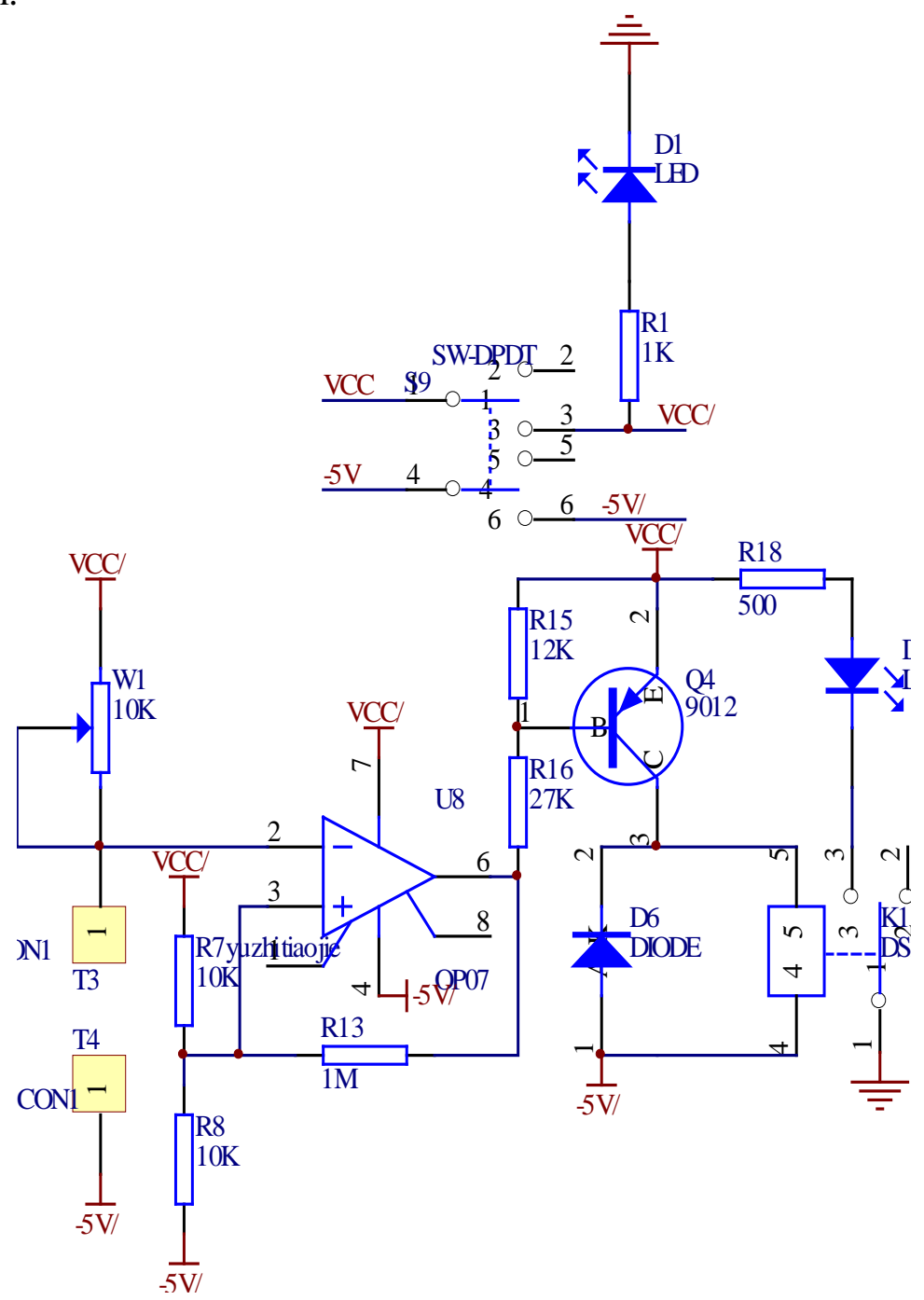

Fig. 3 Light control switch circuit

\section{Data analysis and optical control phenomena}

Parameters analysis. Dark resistance of photoresistors. Dark current testing and recording $\mathrm{I}_{\text {dark }}=2.0 \mu \mathrm{A}, \mathrm{R}_{\text {dark }}=6.0 * 10^{3} \mathrm{~K} \Omega$

Light resistance. Light current measurement and recording: $\mathrm{I}_{\text {light }}=0.996 \mathrm{~mA}, \mathrm{R}_{\text {light }}=1.86 \mathrm{~K} \Omega$

Calculate utilizing optical flow $\mathrm{I}_{\mathrm{P}}=\mathrm{I}_{\text {ligh }} \mathrm{t}-\mathrm{I}_{\text {dark }}=0.994 \mathrm{~mA}$

Volt-ampere characteristic test. Set an illumination of 200 LX not changing, adjusting supply voltages, filling the photocurrent in the following form table respectively, while the measured voltage 
is $2 \mathrm{~V}, 4 \mathrm{~V}, 6 \mathrm{~V}, 8 \mathrm{~V}$ and $10 \mathrm{~V}$; changing the light source illumination 400 lx respectively measured bias voltage is $2 \mathrm{~V}, 4 \mathrm{~V}, 6 \mathrm{~V}, 8 \mathrm{~V}$ and $10 \mathrm{~V}, 12 \mathrm{~V}$, light current fill in Table 1.

Table 1 TACURRENT-VOLTAGE CHARACTERISTIC

\begin{tabular}{|l|l|l|l|l|l|}
\hline Bias voltage & $2 \mathrm{~V}$ & $4 \mathrm{~V}$ & $6 \mathrm{~V}$ & $8 \mathrm{~V}$ & $10 \mathrm{~V}$ \\
\hline $\begin{array}{l}\text { Photo current I } \\
(200 \text { LX) }\end{array}$ & 0.23 & 0.50 & 0.70 & 0.95 & 1.19 \\
\hline $\begin{array}{l}\text { Photo current II (400 } \\
\text { LX) }\end{array}$ & 0.27 & 0.54 & 0.80 & 1.10 & 1.35 \\
\hline
\end{tabular}

Experiment for measuring the illumination characteristics of photoresistance. Set the voltage to 8 $\mathrm{V}$ unchanged, adjusting light intensity meter, in turn tested illumination in $50 \mathrm{~lx}, 100 \mathrm{LX}, 200 \mathrm{LX}$, 300 lx, 400 lx, 500 lx, 600 lx, 700 lx, 800 lx and 900 lx, photocurrent measured and put in TABLE II . Figure 5 shows that light illumination characteristic is nonlinear.

Experiment for measuring the spectral characteristics of photoresistance. Slowly adjust the light intensity adjustment potentiometer to the maximum, S2, S3, S4, S5, S6, S7 up and down in turn, record a minimum value $\mathrm{E}$ as a reference; slowly adjust the potentiometer until the illuminometer displays as E, use multi-meter to record the output data and filling the following form. That is testing out resistance under orange, yellow, green, blue, violet light respectively when the illuminance $\mathrm{E}$. Data in Table 3 corresponds to different wavelengths, sensitivity of the photoresistance is different.

The data of Table 1 is processed by Excel 2007, we can draw volt-ampere characteristic curve. From Figure 4, we can see that the I-U curve is a straight line. Voltage is stable, the stronger the light intensity, the greater the current; light intensity is stable, the greater the voltage, the greater the light current.
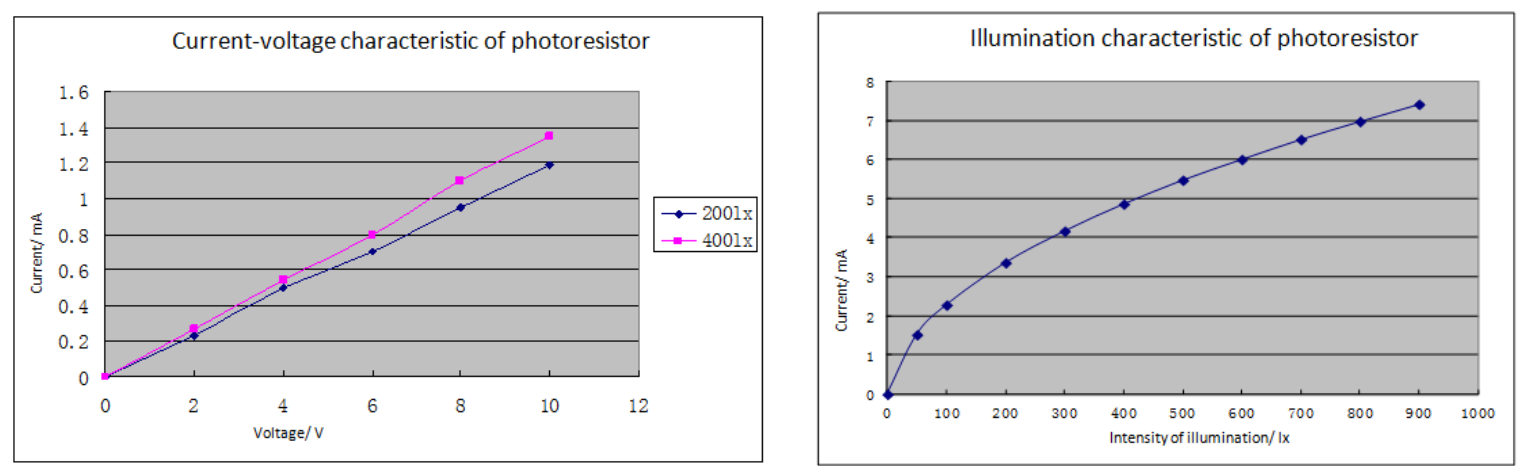

Fig.4 V-I characteristics

Fig. 5 Illumination characteristic of photoresistor

Experiment for measuring the illumination characteristics of photoresistance. Set the voltage to 8 $\mathrm{V}$ unchanged, adjusting light intensity meter, in turn tested illumination in $50 \mathrm{~lx}, 100 \mathrm{~lx}, 200 \mathrm{~lx}, 300$ lx, 400 lx, 500 lx, 600 lx, 700 lx, 800 lx and 900 lx, photocurrent measured and put in Table 2. Figure 5 shows that light illumination characteristic is nonlinear.

Table 2 ILLUMINATION CHARACTERISTIC

\begin{tabular}{|l|l|l|l|l|l|l|l|l|l|l|}
\hline Illumination(lx) & 50 & 100 & 200 & 300 & 400 & 500 & 600 & 700 & 800 & 900 \\
\hline Photo current(mA) & 1.52 & 2.28 & 3.36 & 4.17 & 4.86 & 5.47 & 6 & 6.51 & 6.97 & 7.41 \\
\hline
\end{tabular}


Table 3 SPECTRAL PROPERTIES

\begin{tabular}{|l|l|l|l|l|l|l|}
\hline $\begin{array}{l}\text { Wavelength } \\
(\mathrm{nm})\end{array}$ & $\begin{array}{l}\text { red } \\
(630)\end{array}$ & $\begin{array}{l}\text { orange } \\
(605)\end{array}$ & yellow(585 & gree (520) & Blue (460) & $\begin{array}{l}\text { violet } \\
(400)\end{array}$ \\
\hline Resistance & 8.06 & 13.67 & 10.59 & 9.72 & 16.25 & 12.1 \\
\hline
\end{tabular}

Light control switch analysis. By characteristic tests above we can learn: utilizing a voltage between metal electrodes at both ends, the current is flowing, when light with appropriate wavelength, current will increase if light intensity turns bigger. For photosensitive resistance changes depending on light intensity, it can achieve the purpose of automatic control.

Light control switch schematics, in Figure 3, IN1 and CON1 photoresistor input terminal; U8 the op-amp, the OP07, op-amp comparator circuit. When the voltage output voltage feet 3 is higher than feet 2, transistor Q4 cut off relay does not attached ,and then LEDs will turn off. In contrast, pin 2 output is low, Q4 transistor conductivity, relay electrical conductivity, and LEDs will turn on. And so by changing intensity glazing on photoresistor to control the switching status of the relay, thus controlling LEDs on and off, realizes the function of photo-controlled switch.

\section{Summary}

Using photoresistor experimental apparatus for data collection, data analysis and handling data by Excel 2007 software, you can analyze characteristics of photosensitive resistance; test results are consistent with the theory. After knowing the characteristics of photoresistor, we can built an optical control switch using photo resistor. This experiment system has been used for our college students. This platform can be used for the experiment and practice, emphasizing modular design with detecting and designing system, each module can be independently into a set of teaching system. In this way, students can understand the principles and operation methods of light control switch applications.

\section{References}

[1] B. N. Denisov, “A photoresistor as a multifunctional optoelectronic element,” Journal of Communications Technology and Electronics, vol. 52, pp. 478-481, April 2007.

[2] Wei Jia-dan, and Li Guo-sheng, "Application on LabVIEW in the Teaching Experiment Platform of Special Machine,” Journal of Electrical \& Electronic Education, vol. 33(6), pp. 71-73, 2011.

[3] Yang Dong1, Xuan Kehui2, and Dong Xuefeng, "Characteristics and Applications of Photosensitive Resistance,” Journal of Shandong Polytechnic University Natural Science Edition vol. 27, pp. 49-52, May 2013.

[4] Heng Xiaodong, Wen Chunao, Wang Xiaoping, Liu Xiangdong, and Liu Xu, "Investigation in Grading System of Optical Engineering Lab Courses in World Famous Universities,” Research and Exploration in Laboratory vol. 30, pp. 115-117,147, Jul 2011.

[5] Tan Gan, Chen Jin, Liang Rui, "Exploitation of NI ELVIS-based Innovative Circuit Experiments,” Research and Exploration in Laboratory, vol 29, pp.131-133, 2010 